\title{
Procurement Practices in Project Based Manufacturing Environments
}

\author{
Satya Shah ${ }^{1, a}$ and Syed Hasan ${ }^{2}$ \\ ${ }^{1}$ Faculty of Engineering and Science, University of Greenwich, UK \\ ${ }^{2}$ Industrial and Manufacturing Engineering, NED University of Technology, Pakistan
}

\begin{abstract}
Procurement is one of the processes that cannot be separated in a business. To be able to run a business, it certainly needs to go through procurement stage that involves purchasing raw materials and services. There are many procurement practices in different kinds of business environment such as manufacturing business and construction business. Competitive strategies application within procurement in this manufacturing is very important in order to win a tender for material procurement required in projects. The paper examines how competitive strategies are applied within procurement practice in project-based manufacturing environment. This research studies in the literature of management in engineering, competitive strategy, procurement integration, and case study that takes a sample from the examples of procurement practice application in large organisation such as that of McDermott. The research aims to conduct a qualitative research method based on the discussion and analysis of literature reviews and case study to build conclusions. The findings suggest business players should have core competencies and develop factors such as superior quality, price advantage, on-time delivery, flexibility, and innovation through technology in order to win the competition.
\end{abstract}

\section{Introduction}

In the current unpredictable competition of project-based manufacturing environment, it is very important for business players (both suppliers and manufacturers) to start recognizing the importance of procurement practice because it is one of the most important stages in a business that always requires attention and continuous evaluation. Procurement facilitates acquisition or purchasing of goods and services. That is why, procurement is closely related to a purchase management. In the area of project-based manufacturing, procurement is the connection process of purchasing and arranging in bound movement of all items, supplies, materials, parts, finished inventory and general support services from the suppliers into manufacturing process or assembly plants or warehouses [1]. The final product created in projectbased manufacturing is in the form of final result of a project. It is one of particular manufacturing styles that requires engineering design become unique and sometimes complex in specification. This requires a special attention to business players in implementing this stage. In addition, the actual procurement function is complex processes in which it manages the much wider supply between suppliers and manufacturers and not only buy raw materials and services as mentioned before. The activities in procurement involve the following stages from planning, estimating and identifying the needs; finding, request and evaluation of offers; review and award of contracts; contracting process and

\footnotetext{
${ }^{\text {a }}$ Corresponding author: s.shah@gre.ac.uk
}

administration; until goods are delivered, and the agreement of contract has been reached [2]. Therefore, in recent years, many academics and business practitioners have shown a sense of interest to find out how organisations and suppliers have a control on the manufacturing environment, society, and the economy [3]. Many literatures have been discussed to the subject. From the current literature reviews, we can recognise the procurement practices and strategic principals that will contribute a company to develop the knowledge of linking procurement practices with competitive strategy.

There are a lot of studies about procurement practices in construction business. But it is very difficult to find the in-depth comprehension of procurement practices with the implementation of appropriate competitive strategies within every phase in a project-based manufacturing environment. Whereas the understanding of the competitive procurement strategy is very important to study more in detailed that contribute to competitive advantage of a business. It will help manufacturer to determine how competitive strategy in procurement practices implemented. Moreover, many companies that prefer to do a long-term relationship in the supplier selection process to supply materials required in the project because it is always conducting tendering process, is less effective and efficient. It is not only the partnership strategy can be used to obtain a competitive advantage, but also many factors need to consider by manufacturers in choosing suppliers, even to gain 
competitive advantages. The main contribution of this research is to provide an in-depth knowledge about procurement practices within manufacturing environment between suppliers and manufacturers as a buyer and to establish the suitable competitive procurement strategy especially in required materials procurement during a project. The understanding on how to recognise the process between the manufacturers that conduct the procurement until supplier selection, in which it identifies the procurement steps and recognises factors that should be owned and developed by companies to gain competitive advantages. It also recognises different kinds of procurement strategies from long-term partnership strategy between suppliers and manufacturers to ensure continuous supply of materials and components until competitive strategies to have a success in procurement practices, business outcomes and how to develop it so that a company can find a favourable competitive position in businesses. The scope of this research is in areas of competitive strategy application in procurement practices that are used in project-based manufacturing environment. In order to achieve this, the authors make a limitation on the competitive-related strategy application in manufacturing environment between suppliers and manufacturers only, which conducts the procurement. Therefore, it considers to the given time and the limited availability of data. The strategies except competitive strategy will not be taken into consideration within this research study.

\section{Literature Review}

Effective and efficient procurement require good integrations in each procedure, from making tight cost control to emphasis innovation process by applying a variety of appropriate strategies. The main purpose of procurement practices is to coordinate and integrate every step to fulfil a need for goods and services in a right time with a minimum processing expense, so efficient procurement can be achieved. Hence, it is necessary to understand procurement procedures so that firms can determine suitable strategies to apply. Moreover, partner selection, contract formalization, payment, subcontractor selection, collaborative tools, and performance evaluation have been initiated in a previous research as a control of the project [4].

\subsection{Procurement Procedures}

Procurement procedures can be described as a system of sequential step or the life-cycle stages that begin with defining requirement of procurement, followed by activities involved in the real acquisition of goods or services, until the contract is reached. Because since there are serious implications when procurement procedures are not fulfilled, then it is important for the stakeholders, purchasing departments and others to contribute and interact with the procurement cycle. These are three different phases that can be separated later into different parts of the procurement each of which represent an important step of the procurement phase: Programme planning, procurement stage, and performance monitoring [5].

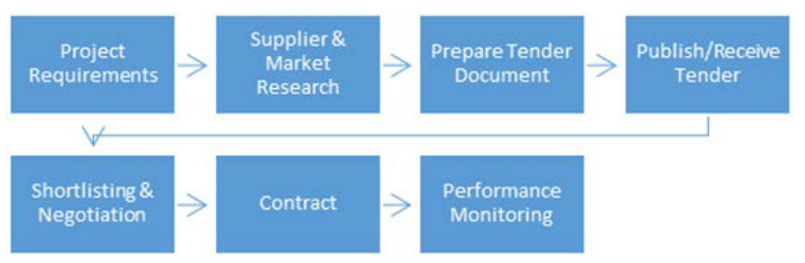

Figure 1. Procurement Process Lifecycle [5]

\subsubsection{Programme Planning}

The beginning phase in the procurement is a planning process which identifies the outcomes and objectives of the procurement. Firms define buying requirements based on the firm's final customer demand. In this step of collecting information, it is very important to define requirement and analyse the supply market because the complexity of this process will vary from case to case. To fulfil the requirement, firms need to define and explain what is needed and will be produced, gather information, identify the proper solution and determine the specification of goods and equipment.

\subsubsection{Procurement Stage}

Sourcing is emphasized in procurement stage. It is defined as a technical activity with the aim of identifying suitable products and services on the market also providing information of supplier qualification criteria to deliver goods and service. Processes such as short-listing, selection of a procurement strategy, supplier selection, negotiation and contract are contained included in this stage. In a contract phase, firms can achieve their efficiencies, flexibility, and sustainable competitive advantage with building supplier and supply chain relationships [6].

\subsubsection{Performance Monitoring}

The main purpose of performance monitoring is to promote economical and efficient procurement. To achieve efficient procurement, the performance of existing suppliers should be monitored continuously. Some firms have developed specific criteria in terms of monitoring supplier performance, for example: the quality of goods and services, delivery times or deadlines, after-sales service, documentation accuracy, responsive action and general collaboration. Firms use the criteria for making a fed back of future sourcing processes. Performance monitoring is also commonly used as firms' indicator for improving performances to achieve best value outcomes by making the service delivery more efficient and coordinated in the future.

\subsection{Project-Based Manufacturing}

Project-based manufacturing, which is also referred to engineer-to-order (ETO) is a manufacturing operation process designed to create similar artificial products with a low inventory level that can be managed as a project. It is one style of particular manufacturing in the industry. In 
ETO's manufacturing, every product which is created is the final result of a project [7]. The final product is created in a manufacturing environment that may require engineering design and the specifications prescribed by the customer and the engineers [8]. Therefore, in the ETO's environment, customer needs are unique and sometimes complex. It is a part of a combination of engineering and manufacturing process. Producing of products is only one part of the project manufacturing, many processes that should be done that need to be integrated to create a better planning and controls of the manufacturing project business [9].

In project-based manufacturing, the methods that are used for mass production planning and control are not suitable to apply in making of the project because the final product is a product that requires unique engineering design or significant customisation. Previous studies considered that an innovative approach to integrate manufacture and logistic with project management is important [10]. ETO sector includes various types of companies, designing, and manufacturing various kinds of products. This enables manufacturers to plan, organise and control the project to produce the final product. ETO companies typically have processes related with the tender, product design, manufacture, installation and contracting. The characteristics of ETO companies can be seen from their markets, products and internal processes of the company. Through the integration, design and product development to respond market demands, product performance improvisation, and a more affordable price to the customers so that the company can improve the efficiency of a product [11].

\subsection{Competitive Strategy}

Business competition determines the success or failure of the firms. Firm's activities such as innovation, a consistent culture, or good implementation take a contribution on its performance. In order to win competition and gain competitive advantages, firms must have proper and good strategy which creates such advantages. But in a business there are many tight and continuous challenges that are very difficult to predict forecast how competition will evolve, so it will be a rare possibility to know for sure whether that firms choose the right strategy or not. The decision of firms' strategy is very important to determine why a customer buys and experiences goods or services continuously over time, and firms must differentiate an organization's value from its competitors [12]. It is why firms must define its business objectives and gather as much information as possible to meet the value of competitive advantages in business. A firm's mission and objectives are a long-term purpose. Figure 2 shows how firms define its mission to get its competitive advantage.

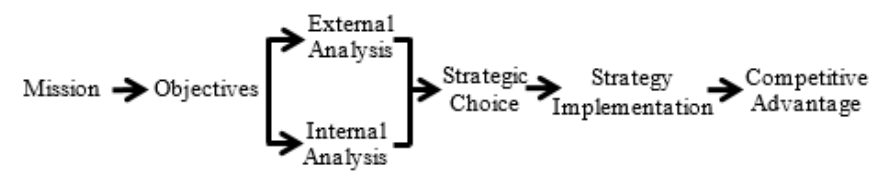

Figure 2. Mission Statement for Competitive Strategy [13]
Competitive advantage in general is when the firm can make more economic value than other competitors. Value is the satisfaction and benefits gained by customers (and other stakeholders) that buy and use firm's products and services [12]. This is important for firms to create unique value for its customer. With a purpose of achieving competitive advantage there is a phase in which firms must choose the strategy. In a large and diversified business, strategy is formulated, evaluated and implemented at three level of organisational strategy:
1. Corporate strategy (highest level)
2. Business strategy (mid - level)
3. Functional/operational strategy (lowest level)

How to succeed competence and achieve competitive advantage are emphasised in business-level strategy. Generally, the business strategy is how the firms develop its distinctive competences and competitive advantages of each unit and compete in the particular business area [14]. It is why firms must have its competitive strategy in the business in which environmental dynamism and manufacturing strategy form a mediating relationship cast in competitive strategy [15]. Competitive strategy is one of the company's efforts in finding a favourable competitive position in business, with the aims to create a profitable and sustainable position in the business competition against many variable forces $[16,17]$. Many authors agree that environment determines the choice of competitive strategy which has a relationship with firm's performance. In their discussion, authors had shown that the dynamics of the environment has a positive relationship with the flexibility and capability of high manufacturers $[18,19]$.

\subsection{Connection of Procurement Procedures with Competitive Strategies}

The procurement procedures generally has the function as defining the characteristic of purchased materials, goods and services; selecting a supplier that can provide goods and service at favourable price and high quality goods; and managing all of aspects in procurement steps so that the goods or services are delivered in a right time. Furthermore, generally manufacturing firm spends around $60 \%$ of its sales on purchasing materials or services, so the importance of procurement significantly affects the successful of the firm's final product [20]. Procurement is now considered as a core of competency of many enterprises and be a main strategic importance [21]. A firm's competitive strategy allows firms determining operations decision that result the preferred performance. In order to gain competitive advantages, manufacturing strategy must be aligned with the company's competitive strategy. It is the same with a strategy in procurement practice, in which all the basic elements of the supply chain must be integrated in order to achieve competitive advantages. Companies can accomplish customer, supplier, and information integration to a higher or lesser level through the design process, purchasing practices like early supplier contribution. 


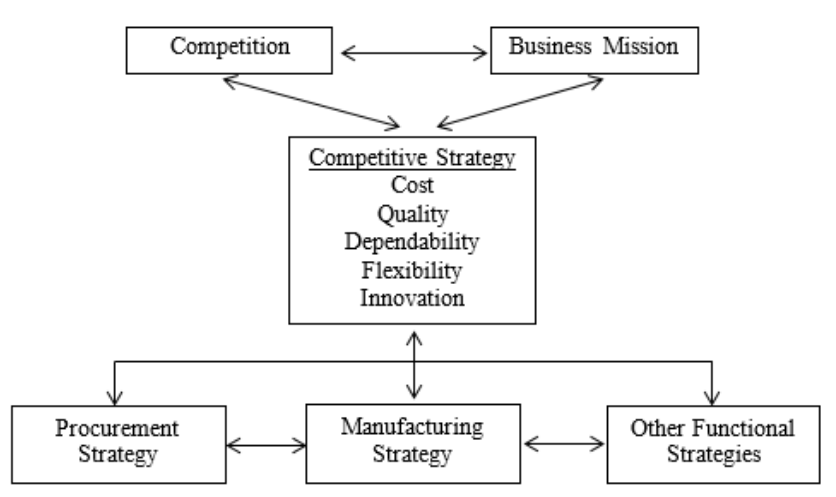

Figure 3. The Relationship of Competitive Strategy and Functional Strategy [22]

Procurement integration may require more than just the application of major purchasing practices such as supplier involvement, supplier development, supplier certification or supply base reduction. Integration in procurement focuses on internal orientation, which aims to align procurement practices with competitive priorities of the company. The procurement integration in the manufacturing and corporate strategy has been discussed into several conceptual frameworks, one of which is framework from existing research [22]. They emphasize the importance of procurement in the business strategy formulation and implementation.

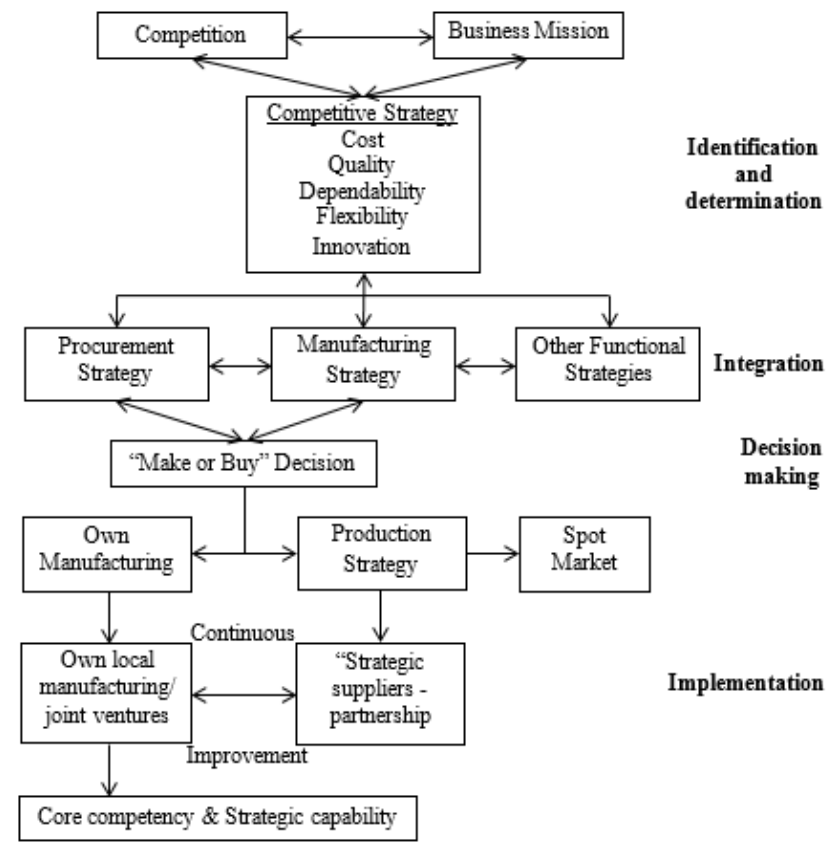

Figure 4. Development of Integrated Procurement Strategy Framework [23]

Since the main purpose of procurement is to support production and operation activities with continuous supply of material and service, so it is necessary to have the consistency between procurement and manufacturing strategy and they must be able to support the company's competitive strategy. The procurement strategy can be seen as a pattern of corporate decisions related to obtaining necessary goods or services for company's operational activities by using overall company's competitive strategies. The relationship of the competitive strategy and functional strategy diagram has shown significant changes in its development. There are four phases that the company must be executed so the competitive advantages are able to be achieved.

\subsection{Supplier Selection}

The project-based manufacturing business characterization makes procurement activities to have an important role in determining the competitiveness of enterprises. The efficient purchasing process in ETO supply chain plays a significant role because more than $60 \%$ of the total price of the product in this business environment is spent for components purchasing. Therefore, the company's performance in this business depends on the performance of its suppliers [24]. In the ETO procurement process, a selection of partners/suppliers is often based on the offers and negotiations, so that, sometimes there are many factors to be considered. Since the main purpose of procurement activities is to get materials/components with a minimum price and available when they are required.

Supplier selection is one of the most important decisions in the procurement of goods. Other studies conducted a broad analysis of the criteria and methods for supplier selection in general. Criteria often used include price, on time delivery and quality. Procurement process begins with the realization of the need for new suppliers, the formulation of decision criteria, manufacturers invite suppliers to make a bid [25]. Followed by a final selection process in monitoring suppliers and next, manufacturers decide to accept or make a counter offer to the selected supplier that will be continued on negotiation step until manufacturers and suppliers reach an agreement [26].

Manufacturers often conduct a study to make sure that they have chosen the right suppliers and applied supplier performance, because it is important for manufacturers to choose suppliers for strategic need and transactional interests and ensures a good corporation. By identifying all of stakeholders' needs of company and improving collaborative relationships between producers and a major supplier for the strategic partnership, it increases the efficiency and benefits of both partners. There are many ways and innovations that can be developed in this collaboration, for example:

1. Communications strategy is needed in the development of corporate strategy;

2. Managed competition is applied to reduce the number of suppliers and consolidate existing suppliers, also supply base segmentation into a more strategic and transactional role;

3. Continuous improvement is carried out through processes such as supplier performance management, in which the supplier's performance is monitored on a regular basis to achieve a certain performance quality level;

4. Value-based compensation is used to convince suppliers and manufacturers in achieving a mutual beneficial objective. 


\section{Research Methodology}

This study focuses towards the use of qualitative research methods towards understanding the application of competitive strategies within procurement practices in project based manufacturing environment to succeed in a competitive sector. This study uses case study based approach with gathering information on procurement practices and competitive strategy application in projectbased manufacturing environment. The research took samples of leading company engaged in the business of EPCI (engineering, procurement, construction and installation).

The case focuses on McDermott International, Inc. ("MII") which is one of the largest states of US-based engineering and construction ("E\&C") companies which concentrates on the offshore upstream oil and gas sector, providing a fully integrated EPCI services. The study analyses different phenomenon and characteristics within the company to provide sufficient knowledge about the development of competitive strategies application in project-based manufacturing environment. The key focus of this study is to provide more detailed explanations of the competitive procurement strategies in project-based manufacturing which has not been fully explored in past studies. Many research studies only examine procurement in the industrial business environment that is usually referred as purchasing, but there is lack of focus towards project-based manufacturing environment.

\section{Case Study Analysis}

The research focuses on the case of McDermott International, Inc.; a leading engineering, procurement, construction and installation ("EPCI") company engaged in designing and implementing complex offshore oil and gas projects in the world. Most of their customers include national, major integrated and other oil and gas companies. Operating in the Atlantic, Caspian, Middle East and Asia Pacific countries (90\% of projects are outside the United States) which are segmented based on regions' proximity, similarities in the environment of services provided, economic characteristics and supervisory responsibility. Providing fully integrated EPCI services, they also make fixed and floating production facilities, pipeline installations and subsea systems from concept to ordering.

Company's resources integration includes employees, various fleets of marine vessels, fabrication facilities and engineering offices. The company's activities are supported by comprehensive project management and procurement service. With abundant capital and company's special abilities in EPCI projects throughout the world create a significant barrier for competitors to enter the global market. However, the company also faces challenges such as tight competition from regional competitors and offshore construction services providers that are less integrated, for example, engineering companies, manufacturing facilities, pipe laying companies and shipbuilders as well as a number of companies that compete with McDermott in each separate phase in EPCI around the world. To encounter competition, the company build the joint venture with a third party through the partnership program becoming strength for the company [27]. The next is the fabrication stage, where on this stage the construction phase begins. For example, on an offshore facilities project, construction work includes packaging, warehousing, weld management, topside and onshore modules, jackets, piles and compliant towers, subsea production systems, also fabrication processes and procedures standardisation. After it is completed, the final process is the installation process, where there are many services offered by McDermott like single and dual heavy lift, float over and various diameter pipeline installation, dynamic positioning systems, subsea installation support. Once the project is completed, the company will conduct commissioning activity. All of data and information used for the project will be added into the historical database, so it is as sources which sometimes can improve the company's performance, scope of work and profitability in the future.

\subsection{Project Operation}

All of the company's operations require raw materials such as carbon and alloy steel in various shapes and components for assembly. The company purchases raw materials and components needed through individual contract. They do not rely on one source of supply for any important raw material. Industry environment where McDermott operates is a very competitive environment and has been contracted to a large number of fixed price projects. In many cases, the company is faced with projects involving complex design and engineering, significant procurement of equipment and supplies, broad construction management and other activities performed in a long period and sometimes in distant locations. So the costs incurred by the company for their projects sometimes exceed of the company's projection. It makes the company covering changes and cost increases with the cost of long-term contracts for labour, materials and services, as well as the estimated increase in costs that reflect to the price of the original contract or price increase clauses [27].

However, despite these efforts, there are still many variations and risks inherent in the industry result in declining profitability and the loss on the project. It is usually caused by a variation in the fixed price contract because of the performance of suppliers, contractors and subcontractors, the company's performance itself, changes in working conditions, unpredictable weather conditions, variations in labour and equipment productivity, and rising in the raw material price, particularly steel price, during the term of the contract.

\subsection{Purchases and Contracts}

Suppliers have a very important role for McDermott and the core business of a company, and contribute to deliver high quality, efficient and competitive solutions for customers. The company acquired all the equipment, supplies and services on the value basis, considering 
suppliers, vendors and sub-contractors fairly and without discrimination, except in some cases where the procurement process is given specifically to certain groups with the purpose of Socioeconomic. The Company applies the highest ethical standards in selecting source, negotiation, determining the award, also managing all purchasing activities so conflict of interest among the company or person can be minimized [27].

\subsection{Procurement Strategies}

Procurement is a very important phase in any McDermott's project, with spare parts and supplies purchased from all over the world and shipped to several international job sites, all parties have a role to play, as each stage of the procurement determines the success of the project. One wrong step happens, then all of which can lead to failure. One effective way arranged by the company to ensure that all steps of the project come together efficiently is EPCI, using one contractor to manage all engineering, procurement, construction and installation process. The company's approach aims to provide more quality control and scrutiny from materials, schedules, and personnel. McDermott's success cannot be separated from the outward expansion conducted by the company and getting competitive bids early. According to the company, it is the correct approach and provides the best opportunity to be competitive due to changing market conditions.

Due to the company's projects are located in different countries, the company continues to develop and use new local supply chain to accommodate the location of the installation as a whole. According to them, choosing the right supplier is a key component to get procurement succeeded. Sometimes they spend a lot of time in the prequalification because of their attention to things, like supplier's financial stability, quality of work, compliance with schedules and response to change. Procurement plan made by the company is also implementing a range of strategies on how they purchase equipment and supplies, how to speed up the requirements examination that will be needed, and how to modify it if there is a change in the project. EPCI approach applied by the company to be very valuable because of the projects, the economic environment and regulatory increasingly become complex, plus involved contractors and vendors, especially iron raw material price continues to fluctuate rapidly.

\section{Analysis and Discussions}

From the case study analysis, it shows that the company is an EPCI company that works in the same environment. McDermott International, Inc. engages in energy sector and complex processing industry. They manage and execute complex engineering and construction project. Most of their customers are large oil and energy companies. The supports of companies are a large capital, special abilities, comprehensive project management and procurement services. In providing good procurement service, the companies must have their own strategy in order to win the competition and create a significant barrier for competitors. The companies are no longer competing at the local level but at the global level so that they face many challenges. The companies run their business based on long-term relationships guidelines with customers and joint venture. The companies build partnerships for the company's force. Procurement becomes an important phase in EPCI project. It is necessary for the companies to make the appropriate competitive strategy in order to win the competition. The companies should be able to improve the integration of design, manufacturing and procurement. Through the integration, the companies can improve their product performances and respond to the market demands that the company can increase their project efficiency.

The products that are produced in a project-based manufacturing is engineered products, which require engineering design, the specifications defined by customers and engineers, and is managed as a project. Most of the tools needed in the projects are industrial tools. They require detailed technical specifications. Although the offered product types are same, but suppliers that offer varied innovations and variations will be able to create a unique advantage and gain a competitive advantage. Product innovation is sometimes required to meet customer's specific requirements that with technology development can do. Innovation used for customisation and products performance development to respond to the demands. Competition in the project-based manufacturing demands the companies to develop their products continuously, so it can compete with other globally. Sourcing innovation is needed to facilitate companies in analysing sourcing process complexities. Information in the portal facilitates the company in sourcing process. So when it is at tendering stage, competent suppliers will be directly able to submit bids for any offered projects. In the bidding stage, big companies will normally use E-procurement that has been commonly used in the tender submission stage.

\section{Conclusions}

The research focused towards the use of competitive strategy within procurement practices in project-based manufacturing environment, with a study of the relationship between competitive strategy and procurement procedures so that both suppliers and manufacturers can find their competitive advantages in business. One of the most effective way is for the company is to recognise their core competencies in order to provide satisfactory advantages to its customers. The authors recognise that the long-term partnership is the effort to make effective tendering process, but both suppliers and manufacturers must limit their dependence with each other so that they are able to reduce the risk of bargaining power threats of both suppliers and manufacturer. Moreover, manufacturers must accurately choose a supplier from the beginning, because a supplier selection can determine the smoothness and success of the procurement until a project is completed. Even 
though the relationship runs very well during a project, then it usually will form a partnership commitment based on trust. So the research identifies that supplier must have competitive strategies that are adapted with company's internal conditions and a competitive environment in order to sustain them continuously in competitions and achieving new businesses.

This study also highlights the need to conduct qualitative research in the future by using other types of strategy approach in order to enrich the content of strategy application literatures to win the tender in a procurement process. The research can be implemented only for the supplier's or manufacturer's point of view. A supplier can be used as a subject in obtaining competitive advantages because a supplier must compete with each other in getting the contract made by the manufacturer. While in a project-based manufacturing, a manufacturer also can turn as a supplier because a manufacturer works as a contractor that focus on a project from a project's owner, so a manufacturer must compete with other manufacturers to obtain project contracts held by the owner. The study also plans towards focusing on a global procurement, as procurement on a global level will be different compared to that of national/regional levels of application.

\section{References}

[1] D.J. Bowersox, D. Closs, M.B. Cooper. Procurement. In: Supply Chain Logistics Management, Second Edition. Singapore: McGraw-Hill, p. 32 (2007)

[2] UN Office for Project Services. Procurement Manual. Revision 4 ed. Copenhagen Denmark: P. P. Group (2010)

[3] H. Walker, W. Phillips. Sustainable Procurement: Emerging Issues. International Public Procurement Conference Proceedings (2006)

[4] P. Eriksson. Achieving suitable coopetition in buyersupplier relationships: The case of AstraZeneca. Journal of Business to Business Marketing, 15(4), 425-454 (2008)

[5] S. Lenny Koh, A. Genovese, A. Acquaye. BIG Energy Upgrade: Procurement and Supply Chain report - Green Deal and Energy Efficiency Retrofitting Supply Chains Delivery, Sheffield Centre for Energy Environment \& Sustainability (2012)

[6] G.N. Nyaga, J.M. Whipple, D.F. Lynch. Examining supply chain relationships: Do buyer and supplier perspectives on collaborative relationships differ. Journal of Operations Management, 28 (2), p. 101-114 (2010)

[7] C.S. Chen. Concurrent engineering-to-order operation in the manufacturing engineering contracting industries. Int. J. Industrial and Systems Engineering, pp. $37-58$ (2006)

[8] N. Cameron, P. Braiden. Using business process reengineering for the development of production efficiency in companies making engineered to order products. Int. J. of Production Economics, pp. 261-273 (2004)

[9] P. Blevins. Project-oriented manufacturing: how to resolve the critical business issues that impact organizational competitiveness. Virginia, APICS International Conference, US (1999)

[10] F. Caron, A. Fiore. Engineer to order companies: how to integrate manufacturing and innovative processes. Int. J. of Project Management, Issue 13 (5) (1995)

[11] N. Cameron, P. Braiden. Using business process reengineering for the development of production efficiency in companies making engineered to order products. Int. J. of Production Economics, pp. 261-273 (2004)

[12] B.J Witcher, V.S Chau. Overview of strategic management. In: F. Rowe, ed. Strategic Management: Principles and Practice, 2nd edition. Hampshire: Andrew Ashwin, p. 5 (2014)

[13] J.B. Barney, W. Hesterly. Strategy and the Strategic Management Process. In: S. Yagan, ed. Strategic Management and Competitive Advantage. New Jersey: Pearson Education (2012)

[14] K. Lysons, B. Farrington. Business-level strategy. In: Purchasing and Supply Chain Management. Essex: Pearson Education Limited, pp. 41-48 (2012)

[15] N. Venkatraman. The concept of fit in strategy research: towards verbal and statistical correspondence. Int. J. of Academy of Management, 24 (4), p. 423-444 (1989)

[16] M.E. Porter. Competitive Strategy: The core Concepts. In: Competitive Advantage: Creating and Sustaining Superior Performance. New York: Free Press (2004)

[17] M.E. Porter. The Value Chain and Competitive Advantage: Creating and Sustaining Superior Performance. New York, 33-59 (2004)

[18] P. Swamidass, W. Newell. Manufacturing Strategy, Environmental Uncertainty and Performance: a path analytic model. Management Science, 33 (4) (1987)

[19] P. Ward, R. Duray, G. Leong, C. Sum, C. Business environment, operations strategy, and performance: an empirical study of Singapore manufacturers. J. of Operations Management, 13 (2), p. 99-115 (1995)

[20] D. Burt. Managing product quality through strategic purchasing Sloan Management Review. Sloan Management Review, Issue 30 (1), pp. 39-47 (1989)

[21] R. Tassabehji, A. Moorhouse. The changing role of procurement: Developing professional effectiveness. J. of Purchasing \& Supply Management, 14, pp. 55-68 (2008)

[22] C. Watts, K. Kim, C. Hahn. Linking purchasing to corporate competitive strategy. Int. J. Purchasing and Materials Management, 28 (4), pp. 2-8 (1992)

[23] V.M. Virolainen. A survey of procurement strategy development in industrial companies. Int. J. of Production Economics, 56, pp. 677-688 (1998)

[24] J. Jahnukainen, M. Lahti. Efficient purchasing in make-toorder supply chains. Int. J. of Production Economics, 59, pp. 103-111 (1999)

[25] C.A. Weber, J.R. Current, W.C. Benton. Vendor selection criteria and method. European J. of Operations Research, 50, pp. 2-18 (1991)

[26] K.L. Choy, W.B. Lee. On the development of a case based supplier management tool for multinational manufacturers. Measuring Business Excellence, 6 (1), pp. $15-22$ (2002)

[27] McDermott International Inc. McDermott International Inc., 2012 Annual Report on Building for Growth, Texas: McDermott International, Inc. c/o Investor Relations (2013) 